\title{
Mímica, suplemento, carnavalização: uma leitura de Grande sertão: veredas, de Guimarães Rosa
}

Luciene Pereira

Mestre em Letras: Estudos Literários (Área de Concentração: Teoria da Literatura)

\begin{abstract}
RESUMO
Os conceitos "mímica” (Bhabha), “suplemento" (Derrida) e “carnavalização” (Bakhtin) norteiam a análise de Grande sertão: veredas, de João Guimarães Rosa, com o sentido de discutir as relações de força articuladas no romance no momento em que a escrita desse livro tem de se medir direta ou indiretamente com questões da ordem do poder.
\end{abstract}

\section{PALAVRAS-CHAVE}

Guimarães Rosa, modernidade, suplemento, carnavalização, mímica

"Ele trouxe um segundo ator."

Jorge Luiz Borges

Essa “frase casual” aqui apresentada como epígrafe deste texto é a mesma com a qual Borges se depara ao folhear uma história da literatura grega, é ela que o desperta para Outras inquisições ao projeto da modernidade, e é Esquilo quem nela assume o local do sujeito pronominal. Detendo-se, Borges constatou que a mesma informação que encerra essa frase "ligeiramente enigmática” consta da Poética de Aristóteles, o mesmo filósofo grego que classificou os gêneros como produtos da voz, com base no modo de representação mimética. Naquela que se tornou obra fundamental da teoria clássica dos gêneros, Aristóteles afirma também ser Ésquilo aquele que 'elevou de um a dois o número de atores’. ${ }^{1}$ Esse novo personagem promove uma profunda variação na estrutura do drama grego e abala a soberania do único ator - chamado: “o hipócrita, - alçado pelos coturnos, trajando preto ou púrpura e com o rosto aumentado por uma máscara, dividia a cena com os doze indivíduos do coro”;

\footnotetext{
${ }^{1}$ BORGES. O pudor da história, p. 120.
} 
aquele outro ator surgiu e instalou-se em cena sem cerimônias de anunciação, mas com ele “entraram em cena o diálogo e as indefinidas possibilidades da reação de uns personagens sobre outros”. ${ }^{2}$

Borges é tomado pela surpresa com que esse acontecimento de rara importância para o universo artístico passou pudorosamente pela história e não apenas o descreve de forma a contextualizá-lo nas conjunturas históricas dos procedimentos da arte, como também o revisa. Em "O pudor da história”, 3 texto que contempla as sucessivas práticas governamentais em forjar ou simular as jornadas históricas, Borges suspeita de que a história, a verdadeira, "é mais pudorosa” ${ }^{4}$ e que as datas essenciais para a mudança da ordem das coisas permanecem, não raro, durante muito tempo, secretas, pois que "os olhos vêem o que estão habituados a ver”. ${ }^{5}$ Pondo em perspectiva o olhar desconstrutor de seu tempo, Borges inquire: "naquele dia de uma primavera remota, naquele teatro da cor do mel, o que eles terão pensado, o que sentiram exatamente?”6 Do mesmo modo como não é possível saber ao certo quais terão sido as reações da espetacular aparição do outro ator diante do público grego, tampouco é possível acertar em qual teria sido a reação do mentor desta feita; sobre Ésquilo “nunca saberemos se pressentiu, sequer de modo imperfeito, quão significativa era essa passagem do um ao dois, da unidade à pluralidade, e assim até o infinito". 7 Também não ultrapassariam o nível da especulação as questões que pudessem ser levantadas sobre a consciência da importância de sua incorporação ao espetáculo, por parte do ator, que naquele momento representou o outro. A evidente inoperância da faculdade de julgar por parte de autor, ator e público nesse episódio é sintomática da ordem geral do pensamento ocidental aludida por Bhabha, ao relembrar que

o signo da história não consiste em uma essência do acontecimento em si, nem exclusivamente na consciência imediata de seus agentes e atores, mas em sua forma enquanto espetáculo - espetáculo que significa por causa do distanciamento e deslocamento entre o acontecimento e seus espectadores. ${ }^{8}$

Vemos que, com o ingresso do segundo ator no drama grego, é possível aí identificar uma outra cena que representa alteridades interditas, invisibilizadas, silenciadas; são outras as

\footnotetext{
${ }^{2}$ BORGES. O pudor da história, p. 121.

${ }^{3}$ BORGES. O pudor da história, p. 120-123.

${ }^{4}$ BORGES. O pudor da história, p. 120.

${ }^{5}$ BORGES. O pudor da história, p. 120.

${ }^{6}$ BORGES. O pudor da história, p. 121.

${ }^{7}$ BORGES. O pudor da história, p. 121.

${ }^{8}$ BHAHBA. O local da cultura, p. 335. (grifos do autor)
} 
agências que a partir da emergência do segundo ator adquirem representação, cidadania e legitimidade no palco grego e se articulam em favor de uma consciência histórica aberta a outras formas de vida.

Se Ésquilo não demorou em suas reflexões acerca da importância dessa “outra cena” que introduzira na Antiguidade, na Contemporaneidade é Homi K. Bhabha, em seu texto “Da mímica e do homem: a ambivalência do discurso colonial”, capítulo IV do seu livro O local da cultura, quem reflete e teoriza acerca de uma não menos importante "outra cena”, qual seja, “a cena do desejo europeu do século 19 por uma consciência histórica autêntica”. 9 Bhabha articula essas reflexões à sua teoria do discurso colonial e defende que é o discurso colonial o que possibilita a emergência dessa outra cena do desejo europeu.

O teórico indiano considera que o processo relacional de constituição das identidades no âmbito da colônia pressupõe um acordo irônico representado pela mímica. A mímica se caracteriza como uma visão dupla que, por revelar a ambivalência do discurso colonial, desestabiliza a sua autoridade. A mímica consiste no reconhecimento parcial do poder hegemônico que articula as perturbações da diferença cultural, racial e histórica, por parte do colonizado. Por tudo isso, o discurso do sujeito colonizado é produzido no lugar da interdição; não deve vir à luz de forma clara. "Deve ser mantido oculto, um discurso proferido nas entrelinhas e, como tal, tanto contra as regras quanto dentro delas." ${ }^{10}$ Esse discurso produz "efeitos de identidade" "conflituosos, fantásticos e discriminatórios”. ${ }^{11}$ Nessa perspectiva, levanta questionamentos graves acerca da legitimação das representações, reavaliando “os saberes normativos da prioridade da raça, da escrita, da história”. ${ }^{12}$

Muito embora Bhabha utilize o conceito de mímica para se referir especificamente ao discurso do espaço colonial, podemos pensá-lo no âmbito do espaço moderno e, de forma específica, no que diz respeito às relações de poder aí também inscritas. Nesse exercício podemos enxergar que a mímica, ao mesmo tempo que viabiliza essa outra cena, permitindo “tornar visível o que não é visto, pode também significar uma mudança de nível, dirigindo-se a uma camada de material que, até então, não tinha pertinência alguma para a história e que não havia sido reconhecida como tendo qualquer valor moral, estético ou histórico”. ${ }^{13}$

\footnotetext{
${ }^{9}$ BHABHA. O local da cultura, p. 137.

${ }^{10}$ BHABHA. O local da cultura, p. 138.

${ }^{11}$ BHABHA. O local da cultura, p. 138.

${ }^{12}$ BHABHA. O local da cultura, p. 138.

${ }^{13}$ Foucault, citado por SPIVAK. Pode o subalterno falar?, p. 61.
} 
Essa “outra cena”, ao ser recuperada do ostracismo a que foi relegada até o século 19, propicia a emergência de outras histórias dignas de cidadania no âmbito da modernidade. Essas outras histórias, ao virem à tona no universo artístico, tornam possível constituir um lugar que confira visibilidade aos seus outros atores.

Spivak relembra que o fato “consistentemente problemático” nesse processo "é o deslize entre tornar o mecanismo visível e tornar o indivíduo vocal”. ${ }^{14}$ Tendo em vista a tese de Spivak de que o subalterno não pode falar, de que ele está condenado a habitar um "centro silencioso e silenciado" em que se constituem "as margens do circuito marcado por essa violência sistêmica”, ${ }^{15}$ acreditamos ser possível identificar no discurso literário de João Guimarães Rosa, em $G S: V$, especificamente, o lugar de representação dessa agência. Se essa agência, por si, não adquire “caráter dialógico"16 no universo real, acreditamos que é no âmbito da fabulação que ela adquirirá a sua articulação. Conforme já mencionara Walnice Nogueira Galvão, “sendo a literatura espaço privilegiado da utopia, é esse mesmo sertão múltiplo que realça o tratamento riquíssimo que Guimarães Rosa dá à alteridade.”17

Nos “patamares da fabulação", ${ }^{18}$ formam-se lugares em que se torna possível dizer “o que se recusa a dizer" para relembrar as palavras de Macherey. ${ }^{19}$ No romance rosiano, em que também se “medem os silêncios”, é possível ao subalterno conquistar um lugar para articular a sua agência banida da ordem do discurso hegemônico, fazendo-se sujeito inapropriado por excelência.

Assim, no sertão mineiro, ainda na década de 1950, Riobaldo articulará também uma outra cena. O sertanejo que ocupa no romance rosiano o local de enunciação ficcional voltase também para acontecimentos aparentemente menores aos olhos da historiografia tradicional para constatar que, na narrativa dos acontecimentos, “o que vale, são outras coisas”. ${ }^{20}$

\footnotetext{
${ }^{14}$ SPIVAK. Pode o subalterno falar?, p. 61.

${ }^{15}$ SPIVAK. Pode o subalterno falar?, p. 54.

${ }^{16}$ ALMEIDA. Prefácio - Apresentando Spivak?, p. 14.

${ }^{17}$ Cf. GALVÃO. Os patamares da fabulação, p. 32.

${ }^{18}$ GALVÃO. Os patamares da fabulação, p. 32.

${ }^{19}$ MACHEREY. A Theory of liberary Production, p. 87, citado por SPIVAK. Pode o subalterno falar?, p. 64.

${ }^{20}$ ROSA. Grande sertão: veredas, p. 132.
} 
Quando outrora Riobaldo declarou - “o senhor não me pergunte nada”, “coisas dessas não se perguntam bem”, “sei que estou contando errado, pelos altos”, “desemendo”-,, ${ }^{21}$ o narrador imitou o conhecido tom da hospitalidade sertaneja, operando nela um desvio que, ao mesmo tempo que lhe permitiu tratar com certa urbanidade o visitante, permitiu-lhe também negar o estabelecimento de um diálogo face a face. Em $G S: V$ verifica-se a operação inversa àquela desenvolvida no texto de Ésquilo. Se a ação de incorporação do segundo ator ao drama, por Ésquilo, permitiu que o diálogo face a face ingressasse nesse gênero e fosse repetido "por multidões de aparências futuras - Hamlet, e Fausto, e Sigismundo, e Macbeth, e Peter Gynt, e outros que nossos olhos ainda não podem discernir”-, como porventura tivesse anunciado um "espectador profético" diante do teatro grego, no romance $G S: V$, ao ingressar em cena o "segundo ator"-, invertem-se as posições de dominador e subalterno ou, como quer Ésquilo, do "hipócrita” e do "segundo ator” e tal diálogo direto é interrompido. ${ }^{22}$ Mas nem por isso cessa o dialogo no texto rosiano, pelo contrário. Em GS:V esse diálogo será feito em muitos outros e sutis níveis de construção discursiva, sendo a inversão de falas entre "segundo ator” e "hipócrita” ${ }^{23}$ talvez a possibilidade menos previsível e de maior impacto no romance.

Como o discurso riobaldiano acena para a "falta anterior de uma presença”, traz em seu bojo um perigo perturbador. Essa falta precisa ser suprida por algo que lhe seja exterior e, logo, aí entendido, um “mal”, "instância subalterna que substitui”, "fora da positividade à qual se ajunta”, “estranho ao que, para ser por ele substituído, deve ser distinto dele”, “um acidente e um afastamento da natureza”. ${ }^{24}$ Logo, em $G S: V$, é possível constatar como a representação de uma agência discursiva objetificada por séculos pode se tornar "uma prática desconfortável, perturbadora, de sobrevivência e suplementaridade - entre a arte e a política, o passado e o presente, o público e o privado - na mesma medida em que seu ser resplandecente é um momento de prazer, esclarecimento ou libertação”, ${ }^{25}$

Na esteira de Bakhtin, Márcia Marques de Morais, em seu ensaio "Sujeito e discurso: algumas considerações sobre a análise do discurso do narrador em 'Grande sertão: veredas'”26, já nos lembrou que, muito embora não possamos destacar a enunciação direta do

\footnotetext{
${ }^{21}$ ROSA. Grande sertão: veredas, p. 131.

22 BORGES. O pudor da história, p. 121.

${ }^{23}$ BORGES. O pudor da história, p. 120-123.

${ }^{24}$ DERRIDA. Gramatologia, p. 178-179.

${ }^{25}$ BHABHA. O local da cultura, p. 245.

${ }^{26}$ MORAIS. Sujeito e Discurso: algumas considerações sobre a análise do discurso do narrador em "Grande Sertão: Veredas".
} 
interlocutor de Riobaldo - esse "senhor” com "suma doutoração” que "seria o citadino para a Crítica em geral” -, seu discurso não está ausente do plano narrativo. E é esse “citadino”

que enceta o diálogo com o sertanejo, tornando o espaço e o tempo textuais, lugares de cruzamento, diálogo e, mais que isso, embate entre dois cronotopos diversos, um tempo arcaico e lugar "sertão" e um tempo moderno e lugar "cidade", para falar no "mundo sertão", usando expressão de Riobaldo e homenageando Antonio Candido.

Além do mais, a emergência da narrativa “desenredada” dos sertanejos rosianos, sujeitos inapropriados por excelência no âmbito do universo da prática escriturística em que a narrativa rosiana em questão se situa de forma monumental e o silenciamento do interlocutor citadino, parece-nos se constituir em uma das mais claras evidências do processo de carnavalização literária em $G S: V$, processo que a partir dessa inversão de posicionamento reverbera no romance ao infinito. Ainda tendo em vista as teses de Bakhtin, ${ }^{27}$ parece-nos que, longe de apresentar semelhanças com gêneros literários sérios tais quais a epopeia e a tragédia, que primam pelos discursos diretos elevados, podemos verificar que no romance há um grande diálogo com a tradição dos gêneros sério-cômicos: pertencentes à tradição da literatura carnavalizada, uma vez que a própria inversão de posicionamentos discursivos entre Riobaldo e o viajante estrangeiro se constitui numa evidência da presença marcada da atualidade, experiência e fantasia livre, pluralidade de estilos e variedade de vozes, características intrínsecas à carnavalização literária.

Por tudo isso, consideramos que Riobaldo, ao assumir as rédeas do discurso e inverter a lógica do discurso colonial, realiza uma operação monumental sem par na literatura brasileira. Seu olhar "nítido como um girassol”28 é capaz de deslocar o colonizador da autoridade de seu local de observador para o de observado; sua voz, ainda que ao contar perca o fio linear da narrativa, aspecto muito peculiar daquele que ainda tateia o solo em que lançará as sementes de seu discurso, é capaz de deslocar a posição do enunciador do discurso hegemônico para o do ouvinte, tecendo "a sua estória puxando fio do discurso prévio do seu ouvinte, bordando embora toda uma outra trama, em que a antiga enunciação mal pode se reconhecer no novo desenho", ${ }^{29}$ A visibilidade que o narrador aí conquista, qual a de um "segundo sol”, ${ }^{30}$ é capaz de realinhar a órbita das funções dos personagens do texto narrativo;

\footnotetext{
${ }^{27}$ BAKHTIN. Problemas da Poética de Dostoievski.

${ }^{28}$ PESSOA. Obra poética II: poemas de Alberto Caeiro.

${ }^{29}$ ÁVILA. O retrato na rua - memórias e modernidade na cidade planejada, p. 106.

${ }^{30}$ ELLER. O segundo sol.
} 
sua “sombra exemplar”,31 obscurece posições seculares na enunciação ficcional, a exemplo da enunciação ficcional do viajante estrangeiro em curso pelo sertão, que por tanto tempo roubou a cena da literatura ficcional brasileira, narrando suas aventuras pelos confins do país, como já nos alertou Süssekind:

É sobretudo num jogo de contrastes e imitações entre prosa de ficção e literatura de viagens, descritivismos e paisagismo, que ele [o narrador de ficção em prosa da literatura brasileira] parece se destacar com maior nitidez nesse quadro. ${ }^{32}$

Para tanto, um dos principais subterfúgios de Rosa na reorientação das rotas e metas do narrador ficcional da literatura brasileira parece consistir na sua "capacidade de dar visibilidade a potencialidades não-realizadas; de agenciar novas redes de sentido; de conciliar experiência e discurso". ${ }^{33}$ Riobaldo, certamente o mais representativo dos narradores da poética rosiana, é capaz de tornar a presença do viajante invisível e abafadas as suas palavras. Partindo desse pressuposto, acreditamos que do diálogo, no sentido bakhtiniano, entre Riobaldo e o viajante estrangeiro em trânsito pelo sertão, longe de permitir-nos visualizar um consenso, é possível daí inferir um confronto. Confronto que está dentro e ao mesmo tempo fora dos limites do texto rosiano, por recuperar não apenas o secular diálogo entre literatura e relato de viagem, mas também por recuperar o processo de desenvolvimento do narrador de ficção no Brasil e de evolução do gênero romanesco na literatura ocidental.

Verifique-se que, mesmo sem conquistar plasticidade no romance, o viajante não sai de cena. Ele ingressa no romance, em diálogo com o narrador Riobaldo, como uma "presença negativa”, uma imagem “fantasmática”, para usar uma expressão de Arlindo Daibert. ${ }^{34}$ Entende-se aqui que esse "fantasma da imagem”, uma vez que não nos apresenta sua face, pode ser tomado como a presença de inúmeros outros viajantes estrangeiros que no sertão mineiro aportaram, por ele se deslocaram e representaram, seguindo o programa do discurso colonialista, a imagem do sertanejo e a imagem do país. Afinal, foi metamorfoseado em viajante que o estrangeiro europeu se apresentou aos olhos dos brasileiros desde o episódio do “descobrimento”. Contudo, se a imagem do fantasma colonial não é nítida, indisfarçável se torna o seu discurso no romance de Rosa, discurso que se faz predeterminado ou, como quer Bhabha, uma "prática enunciativa”. Rosa, por sua vez, sem abster seu narrador de praticar

\footnotetext{
${ }^{31}$ ELLER. O segundo sol.

${ }^{32}$ Cf. SÜSSEKIND. O Brasil não é longe daqui, p. 20, 265.

${ }^{33}$ FANTINI. A poética migrante de Guimarães Rosa, p. 11.

${ }^{34}$ Cf. DAIBERT. Caderno de Escritos, p. 31.
} 
lances ladinos nesse jogo de poder com a imagem do narrador soberano, coloca também o mundo da literatura "à revelia”, carnavalizando-o, a favor da desmontagem dos esquemas narrativos canônicos. Considera-se que essa imagem fantasmática acaba por revelar a precariedade do discurso do narrador rosiano em concretizar o ato de apagamento/arquivamento/rasura do discurso do viajante no discurso literário. Esse esforço não elimina a sua significativa presença, pelo contrário, sua ausência poderia acenar para a impossibilidade da narrativa, tal como ela se nos apresenta. Assim como já alertara Fantini:

[Riobaldo] não possui a autoridade da narrativa épica ou da crônica oficial, e seu testemunho só se tornará exemplar e só terá assegurada sua aura, caso entre em interlocução com uma voz que legitime sua experiência.

É sobretudo nesse sentido que o romance se constrói como um grande diálogo com um homem que, nas palavras de Riobaldo, possui "suma doutoração", o que pode conferir ao testemunho riobaldiano legitimidade e difusão. ${ }^{35}$

É por tudo isso que acreditamos que essa imagem fantasmática do interlocutor de Rosa que está fora, mas ao mesmo tempo dentro do discurso de Riobaldo, fora/dentro do horizonte de expectativas do leitor do romance, será sempre simbolizadora da imagem do estrangeiro em trânsito, pelo sertão, operando o jogo de proximidade e distanciamento, confrontando com o familiar o estranho. Afinal, conforme ainda relembra-nos Süssekind,

diferem os perfis, mas o diálogo persistente com o relato de viagem e o paisagismo - que se procurará examinar aqui - parece sugerir, entre outras coisas, que essas figuras de narrador necessitaram obrigatoriamente de um olhar-de-fora e de uma exibição - consciente ou não - de certa "sensação de não estar de todo" na sua composição. Necessidade que funciona como uma espécie de indicador prévio de deslocamento, distância, desenraizamento, marcas registradas - ora presentes sem que seus autores se apercebam disso, ora trabalhadas propositadamente por eles - da escrita de ficção brasileira. ${ }^{36}$

A perspectiva narrativa adotada por João Guimarães Rosa leva a perceber como, ao operar a remontagem das engrenagens que movem a historiografia oficial e a literatura em prosa brasileira tradicional, a invenção/representação de uma agência discursiva subalterna não validada institucionalmente, e por isso mesmo não tornada possível no universo real, processa-se a ironização e o arremedo crítico, tanto ao discurso falocêntrico dos representantes do poder moderno, quando a falência do poder unificador e legitimador das formas de representação artística da modernidade cujo paradigma se constituiu no grande relato.

\footnotetext{
${ }^{35}$ FANTINI. Guimarães Rosa no 50 de Grande sertão: veredas, p. 42-43.

${ }^{36}$ SÜSSEKIND. O Brasil não é longe daqui, p. 20-21.
} 


\section{ABSTRACT}

The concepts of “mimicry” (H. K. Bhabha), "supplement” (J. Derrida) and “carnivalization” (M. Bakhtin) are the basis of this analysis of Grande sertão: veredas, written by João Guimarães Rosa. I discuss the relations of force articulated in his writing as it directly or indirectly addresses issues of power.

\section{KEYWORDS}

Guimarães Rosa, power, supplement carnivalization, mimicry

\section{REFERÊNCIAS}

ALMEIDA, Sandra Regina Goulart. Prefácio - Apresentando Spivak. In: SPIVAK, Gayatri Chakravorty. Pode o subalterno falar? Trad. Sandra Regina Goulart Almeida, Marcos Pereira Feitosa e André Pereira Feitosa. Belo Horizonte: Editora UFMG, 2010. p. 7-18.

AVILA, M. C. A. O retrato na rua - memórias e modernidade na cidade planejada. Belo Horizonte: Editora UFMG, 2008.

BAKHTIN, Mikhail Mikhaillovich. Problemas da Poética de Dostoievski. Trad. BEZERRA, Paulo. 3. ed. Rio de Janeiro: Forense Universitária, 2005.

BHABHA, Homi K. O local da cultura. Trad. Myriam Ávila, Eliana Lourenço de Lima Reis e Gláucia Renate Gonçalves. Belo Horizonte: Editora UFMG, 2007.

BORGES, Jorge Luiz. O pudor da história. In: . Outras Inquisições. 12. ed. Obras Completas. São Paulo: Globo, 2000. p. 120-123. v. III.

DAIBERT, Arlindo. Caderno de escritos. Org. Júlio Castañon Guimarães. Rio de Janeiro: Sette Letras, 1995.

DERRIDA, Jacques. Gramatologia. 2. ed. Trad. Mirian Chnaiderman. São Paulo: Perspectiva, 2006.

ELLER, C. O segundo Sol. In: Com você...meu mundo ficaria completo. São Paulo: Universal Music Brasil, 1999.

FANTINI, M. Guimarães Rosa no $50^{\circ}$ de Grande sertão: veredas. In: FANTINI, M.; DUARTE, C. L.; ÁVILA, Myriam de Araújo (Org.). O Eixo e a Roda: Revista de Literatura Brasileira (Especial Guimarães Rosa). 12. ed. Belo Horizonte: UFMG, 2006. v. 1. p. 33-54.

FANTINI, M. (Org.). A poética migrante de Guimarães Rosa. Belo Horizonte: Editora UFMG, 2008. 448 p.

GALVÃO, Walnice Nogueira. Os patamares da fabulação. Suplemento Literário de Minas Gerais, Belo Horizonte, p. 32, maio 2006 - Edição especial Guimarães Rosa, 50 Grande sertão: veredas.

MORAIS, Márcia. M. Sujeito e discurso: algumas considerações sobre a análise do discurso 
do narrador em "Grande Sertão: Veredas". [s. d.] Disponível em: $<$ http://www.ich.pucminas.br/posletras/Producao\%20docente/Marcia/Falar\%20de\%20sujeito \%20e\%20discurso.pdf> . Acesso em: 12 maio 2007.

PESSOA, Fernando. Obra poética II: poemas de Alberto Caeiro. Porto Alegre: L\&PM, 2006.

ROSA, J. G. Grande sertão: veredas. 12. ed. Rio de Janeiro: José Olympio, 2001.

SPIVAK, Gayatri Chakravorty. Pode o subalterno falar? Trad. Sandra Regina Goulart Almeida, Marcos Pereira Feitosa e André Pereira Feitosa. Belo Horizonte: Editora UFMG, 2010.

SÜSSENKIND, Flora. O Brasil não é longe daqui. São Paulo: Companhia das Letras, 2000. 